\title{
Predicting Adjuvant Chemotherapy Outcome by Simultaneous Analysis of Thymidylate Synthase Expression and p53 Nuclear Accumulation in Colorectal Cancer
}

\author{
Zihuan Yang ${ }^{1,2}$, Dandan Huang2*, Lekun Fang2, Xingzhi Feng ${ }^{2}$, Huanliang Liu1,2, \\ Lei Wang1,2, Jianping Wang1,2\# \\ ${ }^{1}$ Guangdong Institute of Gastroenterology, Guangzhou, China \\ ${ }^{2}$ Guangdong Provincial Key Laboratory of Colorectal and Pelvic Floor Diseases, The Sixth Affiliated Hospital, Sun \\ Yat-sen University, Guangzhou, China \\ Email: "wjp@mail.sysu.edu.cn
}

Received 25 April 2015; accepted 23 May 2015; published 27 May 2015

Copyright @ 2015 by authors and Scientific Research Publishing Inc.

This work is licensed under the Creative Commons Attribution International License (CC BY).

http://creativecommons.org/licenses/by/4.0/

(c) (i) Open Access

\section{Abstract}

Studies have shown that the tumor suppressor gene p53 may regulate thymidylate synthase (TS) activity in colorectal cancer (CRC) cells, hence attributed to chemo-resistance to 5-flurouracil in CRC. In this study, a total of 299 primary CRC patients who underwent surgery alone or received an adjuvant 5-FU-based chemotherapy were retrospectively studied. TS expression and p53 nuclear accumulation on paraffin embedded primary tumor tissue arrays were immunohistochemically assessed, and their relationship to patient overall survival (OS) and disease free survival (DFS) were analyzed. No correlation was found between TS and p53 expression. p53 nuclear accumulation was significantly correlated with tumor location. In all, multivariate analysis shows that TNM stage is a good indicator of patient survival. TS or p53 is not an independent prognostic or predictive factor in the CRCs. In chemotherapy-treated group, simultaneous analysis of TS and p53 indicates patients in the p53-/TS- or p53+/TS+ group have significant better OS and DFS than the group p53-/TS+ or p53+/TS- $(P<0.01)$. Thus, our study suggests that simultaneous evaluation of both TS and p53 can help to predict the therapeutic effect of CRCs with 5-FU-based adjuvant chemotherapy.

\footnotetext{
*Authors contribute equally to this work.

${ }^{\#}$ Corresponding author.
} 


\section{Keywords}

\section{Colorectal Cancer, p53, TS, 5-FU, Chemotherapy}

\section{Introduction}

Colorectal cancer ranks the third most common cancer globally. Over 1.2 million new cases and 608,700 deaths were estimated to have occurred in 2008 [1]. Surgery with postoperative adjuvant chemotherapy remains the standard treatment for high-risk stage II disease and advanced CRC. Addition of 5-fluorouracil (5-FU), which is the first-line chemotherapy drug, may improve three-year disease-free survival by approximately $25 \%$, but there are still 30\% of colorectal cancer patients will relapse [2].

Identifying molecular markers that can predict clinical outcomes would be of most importance to optimize individual therapy for CRC patients. The mechanism of cytotoxicity of 5-FU has been partially ascribed to the inhibition of the nucleotide synthetic enzyme TS, which consequently induces p53-dependent apoptosis [3]. TS and p53 are most studied markers that are considered to be of potential prognostic and predictive value in CRC. However, controversy remains about their role in colorectal cancer. Studies have indicated that high expression of TS contributes to a favorable prognosis and higher sensitivity to 5-FU [4] [5]. While other groups report opposite results or no correlation between TS levels and the prognosis of CRC [6]-[8]. A number of clinical studies have found that p53 over expression is correlated with patient survival and resistance to 5-FU [9] [10]. However, no clear evidence has proved the value of routine analysis of p53 status to predict CRC treatment response. It is still uncertain that whether p53 alteration will affect the clinical outcome of CRC [11] [12]. Interestingly, studies have demonstrated an interaction between TS and p53. Wild-type p53 can inhibit TS promoter activity [13], whereas, TS can repress p53 translation and result in the evasion of cell apoptosis [14].

In an effort to investigate the relationship of TS and p53, and their potential role as a prognostic or predictive factor, we analyze TS expression and p53 nuclear accumulation in colorectal cancer from 299 patients treated with surgery alone or with adjuvant 5-FU-based chemotherapy.

\section{Materials and Methods}

\subsection{Patients}

The patient cohort consisted of 299 patients, who underwent tumor resection between 2001 and 2006 at the First Affiliated Hospital of Sun Yat-sen University (SYSU). Among them, 75 (25.1\%) patients received adjuvant 5FU-based chemotherapy. Patients who received preoperative chemotherapy and/or radiotherapy were excluded from this study. Clinicopathologic data and follow-up data of enrolled patients were maintained by specialists. The study was approved by the Ethics Review Board of the Sixth Affiliated Hospital of SYSU. A written informed consent from each patient regarding tissue sampling had been obtained.

\subsection{Tissue Microarrays Construction and Immunohistochemistry.}

The paraffin-embedded tissue blocks and the corresponding histological H\&E stained slides were overlaid for tissue TMA sampling. Duplicates of $1 \mathrm{~mm}$ diameter cylinder were punched from representative tumor areas of individual donor tissue block and re-embedded into a recipient paraffin block at a defined position using a tissue-arraying instrument (MiniCore, ALPHELYS, France).

Immunohistochemical staining was performed using the Polink-2 plus ${ }^{\circledR}$ Polymer HRP Detection System (GBI, WA, USA) according to the manufacturer's instructions. After deparaffinization in xylene and rehydration through a graded alcohol series, slides were transferred to sodium citrate buffer (Beijing Dingguo Changsheng Biotech Co. Ltd, \#AR-0511, China) for $15 \mathrm{~min}$ in the microware and left at room temperature for $30 \mathrm{~min}$. Endogenous peroxidase was blocked with $0.3 \%$ hydrogen peroxide for $10 \mathrm{~min}$ at room temperature, then the slides were incubated with primary antibody to human TS (1:100, Proteintech \#15047-1-AP, USA) or p53 (1:50, CST \#2527, USA) overnight, respectively. The p53 (7F5) rabbit monoclonal antibody detects endogenous levels of both wild-type and mutant human p53 protein. Slides were washed three times with phosphate-buffered saline (PBS) and incubated with Polymer Helper (reagent 1, Polink-2 plus ${ }^{\circledR}$ supply) and Poly-HRP anti-Goat IgG (rea- 
gent 2, Polink-2 plus ${ }^{\circledR}$ supply) for 30 min. Then the slides were stained with DAB and counterstained with hematoxylin. For negative control, isotype-matched antibodies were applied. Staining results were reviewed and scored independently by two pathologists (Y.B. and L.F).

For p53 nuclear staining, cells were assessed according to the proportion of nuclear positive cells. The staining pattern was graded from 0 to 4, with 0 being no staining; 1 when < 25\% of the cell nuclei stained positive; 2 when $25 \%$ - 50\% of cell nuclei stained positive; 3 when $50 \%$ - 75\% cells displayed nuclear staining; and 4 when $>75 \%$ cells displayed nuclear staining.

To evaluate TS expression level, each slide was assigned a score for intensity and staining positive pattern. The percentage of positive tumor cells as follows: 1 (up to 25\% of positive cells), 2 ( $25 \%$ - $50 \%$ of positive cells), 3 (50\% - 75\% of positive cells) and 4 (>75\% of positive cells). Intensity scores ranged from 0 - 3: 0 , no staining; 1 , weak; 2 , moderate, 3 , strong. Multiplication of the two scores resulted in a final score ranging from 0 to 12 .

\subsection{Statistical Analysis}

Overall survival (OS) was calculated from the date of surgery to the date of death or the last follow-up time if follow-up was more than 5-years. For disease-free survival (DFS), an event was defined as the first clinical or pathologic evidence of local or distant recurrence.

Receiver Operation Characteristic (ROC) curve analysis was applied to determine the cut off point for tumor "high expression" by using the 0,1-criterion. Under this condition, a score value of 8 was adopted as cut-off for stratification of TS expression into low $\left(\leq 8, \mathrm{TS}^{-}\right)$and high $(>8$, TS + ); for p53 analysis, tumors were classified as p53-positive (p53+) if 50\% or more cells demonstrated p53 nuclear accumulation (score $>2$ ).

The relationship between TS, p53 and clinicopathologic features of CRC patients were analyzed by $\chi^{2}$-test. The Kaplan-Meier method was used for the univariate survival analysis, and the differences between compared groups were assessed by the log-rank test. The Cox proportional hazards regression model was used to compare OS and DFS between marker categories and to obtain risk ratios. All statistical analyses were performed using SPSS software version 16 (Chicago, IL, USA). A value of $\mathrm{P}<0.05$ was considered statistically significant (bilateral).

\section{Results}

\subsection{TS Expression, p53 Nuclear Accumulation and Patient Characteristics}

IHC stainings were assessed using anti-p53 and anti-TS antibodies (Figure 1(C)). In the entire cohort of 299 patients (treated and untreated), 175 (58.5\%) showed high TS expression (TS+) and 138 (46.2\%) showed high p53 nuclear accumulation (p53+). The TS and p53 levels were correlated with the following parameters: sex and age of patients, tumor stage and location, and adjuvant chemotherapy. Positive p53 was seen more frequently in tumors located in the rectum compared to those in the colon $(52.8 \%$ vs. $38.4 \%, \mathrm{P}=0.013)$. No other statistically significant associations were observed (Table 1).

\subsection{Association between TS Expression, p53 Nuclear Accumulation and Prognosis}

The expressions of TS and nuclear staining of p53, as well as other clinicopathologic factors were further examined by Cox regression analysis. Univariate analysis in all patients indicated a significant association between TNM stage and the survival of patients $(\mathrm{P}<0.001$ for both OS and DFS). Tumor located in rectum was associated with a significantly worse OS $(\mathrm{P}=0.004)$ and DFS $(\mathrm{P}=0.004)$. These were confirmed in a multivariate analysis, which revealed that TNM stage and tumor site were independent prognostic factors for CRC patients (Table 2). The significant interaction between tumor location and patient survival may attribute to higher percentage of tumors in rectum exhibited positive p53 nuclear staining. No significantly association between combined phenotypes of TS/p53 and DFS or OS.

\subsection{Combined Effect of p53 and TS on the Survival of Chemotherapy-Treated Patients}

In order to assess the relationship of TS and p53 level with treatment outcome, patients with 5-FU based chemotherapy were analyzed separately. In the chemotherapy-treated patients, 47 (72.3\%) and 33 (44.0\%) of 75 
Table 1. Association of clinical annotations to TS and p53 level in all CRC patients.

\begin{tabular}{|c|c|c|c|c|c|c|c|}
\hline \multirow{2}{*}{ Parameter } & \multirow{2}{*}{$\mathrm{n}$} & \multicolumn{3}{|c|}{ p53 nuclear accumulation } & \multicolumn{3}{|c|}{ TS expression } \\
\hline & & Low & High & $P$ & Low & High & $P$ \\
\hline All patient & 299 & 161 & 138 & & 124 & 175 & \\
\hline Sex & & & & 0.307 & & & 0.610 \\
\hline Male & 166 & 94 & 72 & & 71 & 95 & \\
\hline Female & 136 & 69 & 67 & & 53 & 80 & \\
\hline Age & & & & 0.429 & & & 0.610 \\
\hline$\geq 59$ & 166 & 86 & 80 & & 53 & 80 & \\
\hline$<59$ & 133 & 75 & 58 & & 71 & 95 & \\
\hline Tumor location & & & & 0.013 & & & 0.957 \\
\hline Colon & 138 & 85 & 53 & & 57 & 81 & \\
\hline Rectum & 161 & 76 & 85 & & 67 & 94 & \\
\hline TNM stage & & & & 0.064 & & & 0.317 \\
\hline $1-2$ & 178 & 88 & 90 & & 78 & 100 & \\
\hline $3-4$ & 121 & 73 & 48 & & 46 & 75 & \\
\hline Chemotherapy & & & & 0.484 & & & 0.401 \\
\hline No & 224 & 118 & 106 & & 96 & 128 & \\
\hline Yes & 75 & 43 & 32 & & 28 & 47 & \\
\hline
\end{tabular}

Table 2. Univariate and multivariate analysis of molecular markers and clinicopathologic parameters in relation to OS and DFS in all patients.

\begin{tabular}{|c|c|c|c|c|c|c|c|c|c|}
\hline \multirow{3}{*}{ Parameter } & \multirow{3}{*}{ Value } & \multicolumn{4}{|c|}{ Univariate } & \multicolumn{4}{|c|}{ Multivariate } \\
\hline & & \multicolumn{2}{|l|}{ OS } & \multicolumn{2}{|l|}{ DFS } & \multicolumn{2}{|l|}{ OS } & \multicolumn{2}{|c|}{ DFS } \\
\hline & & HR (95\% CI) & $\mathrm{P}$ & HR (95\% CI) & $\mathrm{P}$ & HR (95\% CI) & $\mathrm{P}$ & HR (95\% CI) & $\mathrm{P}$ \\
\hline Sex & Male & $\begin{array}{c}0.94 \\
(0.61,1.44)\end{array}$ & 0.775 & $\begin{array}{c}0.93 \\
(0.61,1.43)\end{array}$ & 0.749 & & & & \\
\hline Age & $<59$ & $\begin{array}{c}1.47 \\
(0.94,2.32)\end{array}$ & 0.201 & $\begin{array}{c}1.26 \\
(0.82,1.96)\end{array}$ & 0.292 & & & & \\
\hline Tumor location & Rectum & $\begin{array}{c}1.96 \\
(1.24,3.11)\end{array}$ & 0.004 & $\begin{array}{c}1.94 \\
(1.23,3.05)\end{array}$ & 0.004 & $\begin{array}{c}1.71 \\
(1.07,2.73)\end{array}$ & 0.025 & $\begin{array}{c}1.88 \\
(1.20,2.96)\end{array}$ & 0.006 \\
\hline TNM stage & TNM1/2 & $\begin{array}{c}0.36 \\
(0.23,0.56)\end{array}$ & $<0.001$ & $\begin{array}{c}0.37 \\
(0.24,0.57)\end{array}$ & $<0.001$ & $\begin{array}{c}0.36 \\
(0.23,0.57)\end{array}$ & $<0.001$ & $\begin{array}{c}0.38 \\
(0.25,0.59)\end{array}$ & $<0.001$ \\
\hline Chemotherapy & Yes & $\begin{array}{c}1.07 \\
(0.65,1.78)\end{array}$ & 0.788 & $\begin{array}{c}1.05 \\
(0.64,1.72)\end{array}$ & 0.855 & & & & \\
\hline p53 expression & Low & $\begin{array}{c}0.96 \\
(0.62,1.49)\end{array}$ & 0.853 & $\begin{array}{c}0.93 \\
(0.61,1.43)\end{array}$ & 0.739 & & & & \\
\hline TS expression & Low & $\begin{array}{c}1.11 \\
(0.71,1.74)\end{array}$ & 0.638 & $\begin{array}{c}1.14 \\
(0.74,1.76)\end{array}$ & 0.548 & & & & \\
\hline \multirow{3}{*}{ p53/TS level } & $\mathrm{p} 53-/ \mathrm{TS}+$ & $\begin{array}{c}1.72 \\
(0.91,3.25)\end{array}$ & 0.098 & $\begin{array}{c}1.61 \\
(0.88,2.95)\end{array}$ & 0.125 & & & & \\
\hline & p53+/TS- & $\begin{array}{c}1.63 \\
(0.81,3.26)\end{array}$ & 0.170 & $\begin{array}{c}1.42 \\
(0.73,2.77)\end{array}$ & 0.307 & & & & \\
\hline & $\mathrm{p} 53+/ \mathrm{TS}+$ & $\begin{array}{c}1.13 \\
(0.56,2.26)\end{array}$ & 0.741 & $\begin{array}{c}1.10 \\
(0.57,2.13)\end{array}$ & 0.774 & & & & \\
\hline
\end{tabular}


A

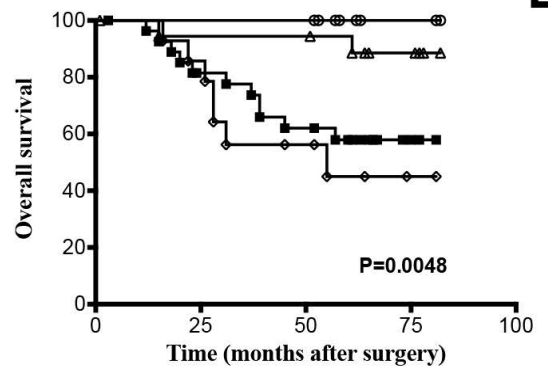

C
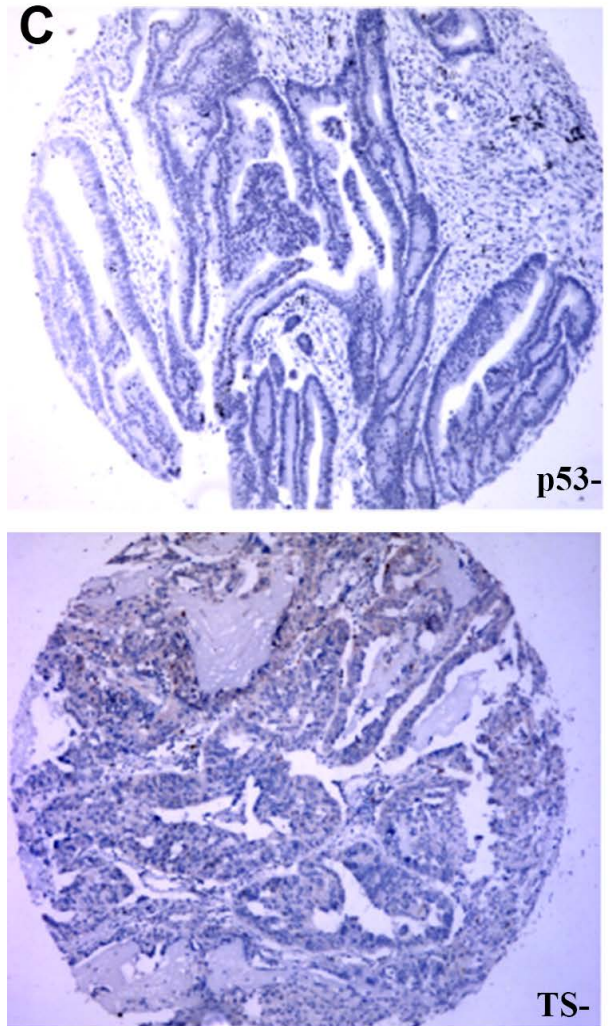

B
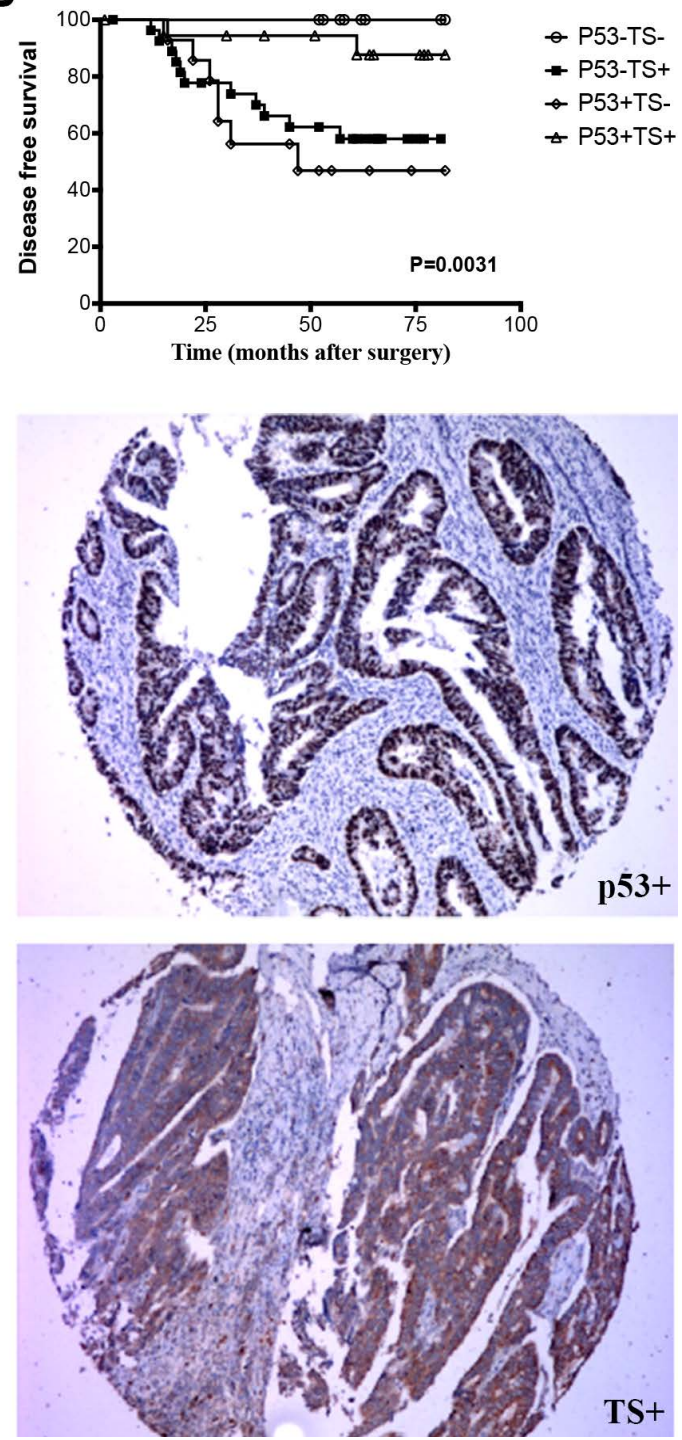

Figure 1. Kaplan-Meier OS (A) and DFS (B) curves of CRC patients received adjuvant chemotherapy caategorized according to different combinations of TS expression and p53 nuclear accumulation. (C) Representative immunohistochemical staining for p53 and TS in colorectal cancer samples.

tumor samples showed TS+ and p53+, respectively. No significant association was found between TS/p53 expression and patient characteristics, such as patient gender, age, TNM stage, and tumor location (Table 3).

According to the p53 and TS statues, patients were divided into the following four groups: p53 positive and TS high (p53+/TS+, $\mathrm{n}=19$ ), p53 negative and TS low (p53-/TS-, $\mathrm{n}=14$ ), p53 negative and TS high (p53-/ TS,$+ n=28)$, p53 positive and TS low (p53+/TS-, $n=14)$. There was no evidence of interaction between TS expression or $\mathrm{p} 53$ nuclear accumulation for either OS $(\mathrm{P}=0.805$ for $\mathrm{p} 53$, and $\mathrm{P}=0.778$ for TS) or DFS $(\mathrm{P}=$ 0.620 for $\mathrm{p} 53$, and $\mathrm{P}=0.899$ for TS). However, multivariate analysis revealed a significant association of combined phenotypes p53+/TS - with a worse OS $(\mathrm{P}=0.022)$ and DFS $(\mathrm{P}=0.025)$ (Table 4). Furthermore, p53-/ TS+ group tended to have worse OS and DFS, although the difference did not reach statistical significance $(\mathrm{P}=$ 0.064 and 0.062 , respectively). Survival curves among the 4 groups differed significantly $(\mathrm{P}=0.0048$ for OS, and $\mathrm{P}=0.0031$ for DFS, Figure 1). These findings indicate that CRC patients treated with 5-FU based chemotherapy could be stratified into better or worse outcome groups by TS expression when p53 nuclear staining was taken into account. 
Table 3. Association of clinical annotations to TS and p53 level in chemotherapy-treated patients.

\begin{tabular}{|c|c|c|c|c|c|c|c|}
\hline \multirow{2}{*}{ Parameter } & \multirow{2}{*}{$\mathrm{n}$} & \multicolumn{3}{|c|}{ p53 nuclear accumulation } & \multicolumn{3}{|c|}{ TS expression } \\
\hline & & Low & High & $P$ & Low & High & $P$ \\
\hline All patient & 75 & 42 & 33 & & 28 & 47 & \\
\hline Sex & & & & 0.954 & & & 0.301 \\
\hline Male & 48 & 27 & 21 & & 20 & 28 & \\
\hline Female & 27 & 15 & 12 & & 8 & 19 & \\
\hline Age & & & & 0.439 & & & 0.446 \\
\hline$\geq 59$ & 31 & 19 & 12 & & 18 & 26 & \\
\hline$<59$ & 44 & 23 & 21 & & 10 & 21 & \\
\hline Tumor location & & & & 0.424 & & & 0.571 \\
\hline Colon & 38 & 23 & 15 & & 13 & 25 & \\
\hline Rectum & 37 & 19 & 18 & & 15 & 22 & \\
\hline TNM stage & & & & 0.525 & & & 0.244 \\
\hline $1-2$ & 39 & 21 & 18 & & 17 & 22 & \\
\hline $3-4$ & 36 & 22 & 14 & & 11 & 25 & \\
\hline
\end{tabular}

Table 4. Univariate and multivariate analysis of molecular markers and clinicopathologic parameters in relation to OS and DFS in chemotherapy-treated patients.

\begin{tabular}{|c|c|c|c|c|c|c|c|c|c|}
\hline \multirow{3}{*}{ Parameter } & \multirow{3}{*}{ Value } & \multicolumn{4}{|c|}{ Univariate } & \multicolumn{4}{|c|}{ Multivariate } \\
\hline & & \multicolumn{2}{|l|}{ OS } & \multicolumn{2}{|l|}{ DFS } & \multicolumn{2}{|l|}{ OS } & \multicolumn{2}{|l|}{ DFS } \\
\hline & & HR (95\% CI) & $\mathrm{P}$ & HR (95\% CI) & $\mathrm{P}$ & HR (95\% CI) & $\mathrm{P}$ & HR $(95 \%$ CI) & $\mathrm{P}$ \\
\hline Sex & Male & $\begin{array}{c}0.59 \\
(0.25,1.43)\end{array}$ & 0.243 & $\begin{array}{c}0.53 \\
(0.27,1.26)\end{array}$ & 0.370 & & & & \\
\hline Age & $<59$ & $\begin{array}{c}1.43 \\
(0.59,3.43)\end{array}$ & 0.427 & $\begin{array}{c}1.58 \\
(0.67,3.73)\end{array}$ & 0.124 & & & & \\
\hline Tumor location & Colon & $\begin{array}{c}2.02 \\
(0.81,5.06)\end{array}$ & 0.135 & $\begin{array}{c}2.08 \\
(0.84,5.18)\end{array}$ & 0.092 & & & & \\
\hline TNM stage & TNM1/2 & $\begin{array}{c}0.40 \\
(0.16,1.01)\end{array}$ & 0.054 & $\begin{array}{c}0.43 \\
(0.18,1.05)\end{array}$ & 0.045 & $\begin{array}{c}0.34 \\
(0.13,0.88)\end{array}$ & 0.026 & $\begin{array}{c}0.36 \\
(0.14,0.91)\end{array}$ & 0.031 \\
\hline $\begin{array}{l}\text { p53 nuclear } \\
\text { accumulation }\end{array}$ & Low & $\begin{array}{c}0.89 \\
(0.37,2.19)\end{array}$ & 0.805 & $\begin{array}{c}0.80 \\
(0.33,1.93)\end{array}$ & 0.499 & & & & \\
\hline TS expression & Low & $\begin{array}{c}1.14 \\
(0.45,2.86)\end{array}$ & 0.778 & $\begin{array}{c}1.06 \\
(0.44,2.56)\end{array}$ & 0.863 & & & & \\
\hline \multirow{3}{*}{ p53/TS level } & p53-/TS+ & $\begin{array}{c}1.95 \\
(0.75,5.12)\end{array}$ & 0.056 & $\begin{array}{c}4.41 \\
(0.95,20.48)\end{array}$ & 0.058 & $\begin{array}{c}6.95 \\
(0.90,23.92)\end{array}$ & 0.064 & $\begin{array}{c}4.36 \\
(0.93,20.53)\end{array}$ & 0.062 \\
\hline & p53+/TS- & $\begin{array}{c}2.15 \\
(0.82,5.60)\end{array}$ & 0.040 & $\begin{array}{c}5.10 \\
(1.00,25.91)\end{array}$ & 0.050 & $\begin{array}{c}12.12 \\
(1.42,33.23)\end{array}$ & 0.022 & $\begin{array}{c}6.67 \\
(1.27,25.05)\end{array}$ & 0.025 \\
\hline & p53+/TS+ & $\begin{array}{c}0.34 \\
(0.12,0.96)\end{array}$ & 0.680 & $\begin{array}{c}0.87 \\
(0.12,6.22)\end{array}$ & 0.893 & & & & \\
\hline
\end{tabular}

\section{Discussion}

In the present study, we find that the immunohistochemical analysis of p53 and TS in colorectal cancer may be useful to predict the survival of patients who have received 5-FU based chemotherapy. TS or p53 alone is not an independent marker for the survival in CRC patients. However, the combination of the two markers acts as a good indicator for predicting 5-FU based chemotherapy outcome. 
The tumor suppressor p53 is one of the most frequently mutated genes in human CRC [15] [16]. Compare to wild-type protein, the mutated p53 protein has a great stability, a significantly longer half-life and accumulated in tumor cells thus could be detected by IHC. It has been believed that 5-FU can activate p53-dependent apoptosis by incorporation of fluoronucleotides into RNA and DNA [3] [17]. Cells with p53 mutations are less sensitive to 5-FU than cells with wild-type 5-FU [18]. A study finds that an elevated expression of wild-type p53 is associated with better survival in CRC patients treated with adjuvant chemotherapy [19]. However, other studies have concluded that abnormal p53 has no effect on the chemotherapy treatment outcome [20] [21]. In our study, we find that p53 expression is associated with tumor location, but not associated with patient OS or DFS, no matter if the patient receives chemotherapy treatment. Further study of the cellular mechanisms of p53 in responses to 5-FU may provide insights into how this important gene functions. It is worth to notice that the sensitivity and specificity of the immunohistochemical assay may affect the correlation between molecular markers and clinical outcome. The antibody we use for p53 recognizes both wild-type and mutant forms of the p53 protein. Consequently, the present results might require further studies in which other mAbs or molecular analysis for different type of p53 detection is tested.

TS is a key enzyme in catalyzing the methylation of deoxythymidine to thymidylate, an essential precursor for DNA replication [22] [23]. Therefore, the first-line chemotherapy treatment of CRC is based upon the inhibition of TS level by 5-FU [24] [25]. However, controversy remains about the prognostic and predictive significance of the expression of TS [7] [26]-[29]. Our results suggest that TS is not an independent prognostic or predictive factor in CRC. In vitro studies have shown that TS is capable of binding to several cellular RNA species, including p53 mRNA, resulting in translational repression [30] [31]. Thus, in addition to the incomplete inhibition of TS through direct binding by 5-FU metabolite, the relevance of high TS and the resistance to 5-FU are considered to due to p53 suppression by TS, which consequently causes impaired cell cycle control and an inability of tumor cells to undergo apoptosis [32]. It is possible to hypothesize that the failure to predict patient survival of TS is possibly because of the regardless of p53 status. Paradiso et al. previously reported that the p53+/TS- tumors responded better to chemotherapy than other groups [21]. But we notice that their follow-up time is relatively short, and the patient number in p53+/TS- group is too small compared to other groups, which may result in a bias. Our analysis for the first time indicates that patients in the TS+/p53+ and TS-/p53- group have better OS and DFS than the other two groups. This can be explained by several ways: 1) When both TS and p53 level is low, 5-FU can effectively inhibit tumor DNA synthesis by direct binding to free TS; 2) When both TS and p53 is high, p53 high expression can rescue the drug resistance phenotype caused by the suppression of p53 by high TS.

Our results demonstrate that the analysis of TS and p53 together can be important in predicting chemotherapeutic efficacy in CRC patients to 5-FU based chemotherapy. Further studies on larger cohort are needed to verify the correlation between p53 and TS and clinical outcome in CRC patients treated with 5-FU based chemotherapy. If our observation is confirmed, TS and p53 status will need to be evaluated as a stratification criterion in future adjuvant treatment.

\section{Acknowledgements}

This study was supported by the Scientific Research Foundation for the Returned Overseas Chinese Scholars of Ministry of Education (No. 201300000237) and Medical Scientific Research Foundation of Guangdong Province (No. B2013161).

\section{References}

[1] Jemal, A. (2011) Global Cancer Statistics (Vol. 61, Page 69, 2011). CA: A Cancer Journal for Clinicians, 61, $134-134$. http://dx.doi.org/10.3322/Caac.20115

[2] Monga, D.K. and O’connell, M.J. (2006) Surgical Adjuvant Therapy for Colorectal Cancer: Current Approaches and Future Directions. Annals of Surgical Oncology, 13, 1021-1034. http://dx.doi.org/10.1245/Aso.2006.08.015

[3] Longley, D.B., Boyer, J., Allen, W.L., Latif, T., Ferguson, P.R., Maxwell, P.J., McDermott, U., Lynch, M., Harkin, D.P. and Johnston, P.G. (2002) The Role of Thymidylate Synthase Induction in Modulating p53-Regulated Gene Expression in Response to 5-Fluorouracil and Antifolates. Cancer Research, 62, 2644-2649.

[4] Edler, D., Glimelius, B., Hallstrom, M., Jakobsen, A., Johnston, P.G., Magnusson, I., Ragnhammar, P. and Blomgren, H. (2002) Thymidylate Synthase Expression in Colorectal Cancer: A Prognostic and Predictive Marker of Benefit from 
Adjuvant Fluorouracil-Based Chemotherapy. Journal of Clinical Oncology, 20, 1721-1728. http://dx.doi.org/10.1200/Jco.2002.07.039

[5] Johnston, P.G., Fisher, E.R., Rockette, H.E., Fisher, B., Wolmark, N., Drake, J.C., Chabner, B.A. and Allegra, C.J. (1994) The Role of Thymidylate Synthase Expression in Prognosis and Outcome of Adjuvant Chemotherapy in Patients with Rectal Cancer. Journal of Clinical Oncology, 12, 2640-2647.

[6] Chen, Y., Yi, C.H., Liu, L., Li, B., Wang, Y.W. and Wang, X.W. (2012) Thymidylate Synthase Expression and Prognosis in Colorectal Cancer: A Meta-Analysis of Colorectal Cancer Survival Data. The International Journal of Biological Markers, 27, 203-211. http://dx.doi.org/10.5301/Jbm.2012.9584

[7] Ohrling, K., Edler, D., Hallstrom, M., Ragnhammar, P. and Blomgren, H. (2005) Detection of Thymidylate Synthase Expression in Lymph Node Metastases of Colorectal Cancer Can Improve the Prognostic Information. Journal of Clinical Oncology, 23, 5628-5634. http://dx.doi.org/10.1200/JCO.2005.12.130

[8] Popat, S., Matakidou, A. and Houlston, R.S. (2004) Thymidylate Synthase Expression and Prognosis in Colorectal Cancer: A Systematic Review and Meta-Analysis. Journal of Clinical Oncology, 22, 529-536. http://dx.doi.org/10.1200/Jco.2004.05.064

[9] Brand, L., Munding, J., Pox, C.P., Ziebarth, W., Reiser, M., Huppe, D., Schmiegel, W., Reinacher-Schick, A. and Tannapfel, A. (2013) ss-Catenin, Cox-2 and p53 Immunostaining in Colorectal Adenomas to Predict Recurrence after Endoscopic Polypectomy. International Journal of Colorectal Disease, 28, 1091-1098. http://dx.doi.org/10.1007/s00384-013-1667-z

[10] Pancione, M., Forte, N., Campione, S., Napolitano, A., Parente, D., Sabatino, L., Febbraro, A. and Colantuoni, V (2010) The High Expression of p53 in Sporadic Colorectal Carcinoma Is Associated with Metastasis and Decreased Survival. Pathologica, 102, 51-56.

[11] Conlin, A., Smith, G., Carey, F.A., Wolf, C.R. and Steele, R.J. (2005) The Prognostic Significance of K-Ras, p53, and APC Mutations in Colorectal Carcinoma. Gut, 54, 1283-1286. http://dx.doi.org/10.1136/gut.2005.066514

[12] Katkoori, V.R., Shanmugam, C., Jia, X., Vitta, S.P., Sthanam, M., Callens, T., Messiaen, L., Chen, D., Zhang, B., Bumpers, H.L., Samuel, T. and Manne, U. (2012) Prognostic Significance and Gene Expression Profiles of p53 Mutations in Microsatellite-Stable Stage III Colorectal Adenocarcinomas. PloS ONE, 7, e30020. http://dx.doi.org/10.1371/journal.pone.0030020

[13] Lee, Y., Chen, Y., Chang, L.S. and Johnson, L.F. (1997) Inhibition of Mouse Thymidylate Synthase Promoter Activity by the Wild-Type p53 Tumor Suppressor Protein. Experimental Cell Research, 234, 270-276. http://dx.doi.org/10.1006/excr.1997.3605

[14] Lowe, S.W., Ruley, H.E., Jacks, T. and Housman, D.E. (1993) P53-Dependent Apoptosis Modulates the Cytotoxicity of Anticancer Agents. Cell, 74, 957-967. http://dx.doi.org/10.1016/0092-8674(93)90719-7

[15] Aylon, Y. and Oren, M. (2007) Living with p53, Dying of p53. Cell, 130, 597-600. http://dx.doi.org/10.1016/j.cell.2007.08.005

[16] Petitjean, A., Mathe, E., Kato, S., Ishioka, C., Tavtigian, S.V., Hainaut, P. and Olivier, M. (2007) Impact of Mutant p53 Functional Properties on TP53 Mutation Patterns and Tumor Phenotype: Lessons from Recent Developments in the IARC TP53 Database. Human Mutation, 28, 622-629. http://dx.doi.org/10.1002/humu.20495

[17] Longley, D.B., Harkin, D.P. and Johnston, P.G. (2003) 5-Fluorouracil: Mechanisms of Action and Clinical Strategies. Nature Reviews Cancer, 3, 330-338. http://dx.doi.org/10.1038/nrc1074

[18] Bunz, F., Hwang, P.M., Torrance, C., Waldman, T., Zhang, Y., Dillehay, L., Williams, J., Lengauer, C., Kinzler, K.W. and Vogelstein, B. (1999) Disruption of p53 in Human Cancer Cells Alters the Responses to Therapeutic Agents. The Journal of Clinical Investigation, 104, 263-269. http://dx.doi.org/10.1172/JCI6863

[19] Huh, J.W., Kim, H.R. and Kim, Y.J. (2013) Prognostic Role of p53 Messenger Ribonucleic Acid Expression in Patients after Curative Resection for Stage I to III Colorectal Cancer: Association with Colon Cancer Stem Cell Markers. Journal of the American College of Surgeons, 216, 1063-1069. http://dx.doi.org/10.1016/j.jamcollsurg.2013.01.058

[20] Munro, A.J., Lain, S. and Lane, D.P. (2005) P53 Abnormalities and Outcomes in Colorectal Cancer: A Systematic Review. British Journal of Cancer, 92, 434-444. http://dx.doi.org/10.1038/sj.bjc.6602358

[21] Paradiso, A., Simone, G., Petroni, S., Leone, B., Vallejo, C., Lacava, J., Romero, A., Machiavelli, M., De Lena, M., Allegra, C.J. and Johnston, P.G. (2000) Thymidilate Synthase and p53 Primary Tumour Expression as Predictive Factors for Advanced Colorectal Cancer Patients. British Journal of Cancer, 82, 560-567. http://dx.doi.org/10.1054/bjoc.1999.0964

[22] Carreras, C.W. and Santi, D.V. (1995) The Catalytic Mechanism and Structure of Thymidylate Synthase. Annual review of biochemistry, 64, 721-762. http://dx.doi.org/10.1146/annurev.bi.64.070195.003445

[23] Wilson, P.M., Danenberg, P.V., Johnston, P.G., Lenz, H.J. and Ladner, R.D. (2014) Standing the Test of Time: Targeting Thymidylate Biosynthesis in Cancer Therapy. Nature Reviews Clinical Oncology, 11, 282-298. 
http://dx.doi.org/10.1038/nrclinonc.2014.51

[24] Danenberg, P.V., Malli, H. and Swenson, S. (1999) Thymidylate Synthase Inhibitors. Seminars in Oncology, 26, 621631.

[25] Rose, M.G., Farrell, M.P. and Schmitz, J.C. (2002) Thymidylate Synthase: A Critical Target for Cancer Chemotherapy. Clinical Colorectal Cancer, 1, 220-229. http://dx.doi.org/10.3816/CCC.2002.n.003

[26] Allegra, C.J., Paik, S., Colangelo, L.H., Parr, A.L., Kirsch, I., Kim, G., Klein, P., Johnston, P.G., Wolmark, N. and Wieand, H.S. (2003) Prognostic Value of Thymidylate Synthase, Ki-67, and p53 in Patients with Dukes' B and C Colon Cancer: A National Cancer Institute-National Surgical Adjuvant Breast and Bowel Project Collaborative Study. Journal of Clinical Oncology, 21, 241-250. http://dx.doi.org/10.1200/JCO.2003.05.044

[27] Edler, D., Glimelius, B., Hallstrom, M., Jakobsen, A., Johnston, P.G., Magnusson, I., Ragnhammar, P. and Blomgren, H. (2002) Thymidylate Synthase Expression in Colorectal Cancer: A Prognostic and Predictive Marker of Benefit from Adjuvant Fluorouracil-Based Chemotherapy. Journal of Clinical Oncology, 20, 1721-1728. http://dx.doi.org/10.1200/JCO.2002.07.039

[28] Nakagawa, T., Shimada, M., Kurita, N., Iwata, T., Nishioka, M., Yoshikawa, K., Higashijima, J. and Utsunomiya, T. (2012) Thymidylate Synthase (TS) Protein Expression as a Prognostic Factor in Advanced Colorectal Cancer: A Comparison with TS mRNA Expression. Hepato-Gastroenterology, 59, 1059-1062.

[29] Westra, J.L., Hollema, H., Schaapveld, M., Platteel, I., Oien, K.A., Keith, W.N., Mauritz, R., Peters, G.J., Buys, C.H., Hofstra, R.M. and Plukker, J.T. (2005) Predictive Value of Thymidylate Synthase and Dihydropyrimidine Dehydrogenase Protein Expression on Survival in Adjuvantly Treated Stage III Colon Cancer Patients. Annals of Oncology, 16, 1646-1653. http://dx.doi.org/10.1093/annonc/mdi316

[30] Chu, E., Cogliati, T., Copur, S.M., Borre, A., Voeller, D.M., Allegra, C.J. and Segal, S. (1996) Identification of in Vivo Target RNA Sequences Bound by Thymidylate Synthase. Nucleic Acids Research, 24, 3222-3228. http://dx.doi.org/10.1093/nar/24.16.3222

[31] Chu, E., Copur, S.M., Ju, J., Chen, T.M., Khleif, S., Voeller, D.M., Mizunuma, N., Patel, M., Maley, G.F., Maley, F. and Allegra, C.J. (1999) Thymidylate Synthase Protein and p53 mRNA form an in Vivo Ribonucleoprotein Complex. Molecular and Cellular Biology, 19, 1582-1594.

[32] Ju, J., Pedersen-Lane, J., Maley, F. and Chu, E. (1999) Regulation of p53 Expression by Thymidylate Synthase. Proceedings of the National Academy of Sciences of the United States of America, 96, 3769-3774. http://dx.doi.org/10.1073/pnas.96.7.3769 